\title{
0592 CHILD AND YOUNG PERSON SAFETY
}

I ljeoma* Correspondence: International Children School, Amah-Isiguzo, Okpular-mbutu, ode-ukwu Aut. comm. Umuode Osisioma, 234, Nigeria

\subsection{6/ip.2010.029215.592}

Proper living entails that one should live and fulfil ones purpose in life.To achieve this one needs a condusive environment devoid of any danger capable of terminating life. A child from birth is helpless up to the point that to feed, clean up his body after a mess or even stay out of danger, needs assistance from grown ups until he gradually becomes independent and capable of doing certain things by himself. Safety is a very important factor in the up bringing of the children because after birth, a child lives and grows in a given environment. And to grow well, the child needs guidance and protection because the environment is laced with dangerous objects and 


\section{IP Safety 2010 abstracts}

it could be unsafe for any growing child. The house floor for instance, whether rough or smooth, the cutleries, breakable plates, gallon of kerosene, stove or gas cooker in the kitchen could be sources of danger. The table, chairs, drugs in the shelf, level of ventilation, electric appliances, uncovered soak-away pits, bad roads, improper rubbish disposal systems, exposing young ones to hawking etc. are all potential harzards capable of wounding or terminating life depending on how they are arranged, organised and managed. This study, therefore,tries to high-light the dangers most objects in the environment pose to children and young ones and how to manage them. 